\title{
Working memory as a factor mediating explicit and implicit knowledge of English grammar
}

\author{
Mirosław Pawlak ${ }^{1,2 *}$ and Adriana Biedron ${ }^{3}$ \\ ${ }^{1}$ Adam Mickiewicz University, Kalisz, Poland, ${ }^{2}$ State University of Applied Sciences, Konin, Poland and \\ ${ }^{3}$ Pomeranian University, Słupsk, Poland \\ *Corresponding author. Email: pawlakmi@amu.edu.pl
}

\begin{abstract}
This paper reports the findings of a study that investigated the relationship between phonological short-term memory (PSTM), working memory capacity (WMC), and the level of mastery of L2 grammar. Grammatical mastery was operationalized as the ability to produce and comprehend English passive voice with reference to explicit and implicit (or highly automatized) knowledge. Correlational analysis showed that PSTM was related to implicit productive knowledge while WMC was linked to explicit productive knowledge. However, regression analysis showed that those relationships were weak and mediated by overall mastery of target language grammar, operationalized as final grades in a grammar course.
\end{abstract}

Keywords: working memory; phonological short-term memory; working memory capacity; explicit knowledge; implicit knowledge

It has long been argued that individual differences (IDs) play an important role in shaping the process of learning a second or foreign language (L2). The effectiveness of instructional techniques and the ultimate mastery of the target language (TL) proficiency may ultimately be moderated by these IDs (Ellis, 2008; Pawlak, 2020). One such ID factor is working memory (WM), or a system that makes it possible to temporarily store and process small amounts of incoming information in the performance of cognitive tasks (Baddeley, 2015). There is copious empirical evidence that WM constitutes a powerful factor impacting L2 learning (Wen et al., 2017), and the acquisition of L2 grammar. Of particular relevance are two components of this memory system: phonological short-term memory (PSTM; the ability to temporarily retain verbal information) and working-memory capacity (WMC; the amount of information that can be simultaneously processed in real time) (Li, et al., 2019; Wen \& Li, 2019).

A crucial issue that still remains unresolved, however, is the contribution of PSTM and WMC to explicit (conscious and declarative) and implicit (intuitive, procedural, and automatized) knowledge of L2 grammar (DeKeyser, 2017). Although many studies have investigated the link between PSTM and WMC and the production and comprehension of grammar (e.g., Martin \& Ellis, 2012), just a handful have addressed their differential effects on explicit and implicit knowledge (Li et al., 2019; Tagarelli, et al., 2015), let alone production and comprehension drawing on these two types of representation.

(c) The Author(s), 2021. Published by Cambridge University Press. This is an Open Access article, distributed under the terms of the Creative Commons Attribution licence (http://creativecommons.org/licenses/by/4.0/), which permits unrestricted re-use, distribution, and reproduction in any medium, provided the original work is properly cited. 
Following the recommendations of WM researchers (e.g., Li et al., 2019; Wen \& Li, 2019), this study examines the predictive role of PSTM and WMC with respect to the productive and receptive dimensions of the explicit and implicit knowledge of the passive in L2 English. Two important caveats should first be made, however. First, the terms "explicit knowledge" and "implicit knowledge" are not used here in the strict psychological sense of the presence or absence of awareness of TL features but in the less rigorous sense adopted by Ellis (2005). Thus, implicit knowledge is understood as knowledge that can be applied in situations in which conscious access to requisite rules is difficult because of time constrains or task conditions, as is the case with realtime interaction. On the other hand, explicit knowledge refers to knowledge that can be employed when learners have ample time to draw on relevant rules but cannot provide a basis for spontaneous communication. Second, the study is part of a larger-scale research project, looking into the role of different facets of WM, initial results of which for a smaller group of participants were reported by Pawlak and Biedron (2019). With these in mind, the study addressed the following two research questions:

- RQ1: What is the relationship between PSTM and WMC and the productive and receptive dimensions of the explicit and implicit knowledge of the English passive voice?

- RQ2: How do PSTM, WMC, and overall mastery of grammar contribute to different types of knowledge of the English passive voice?

\section{Participants}

The participants were 171 Polish university students majoring in English, 116 females and fifty-five males. They were enrolled in years one, two, and three of a three-year BA program that aimed to develop a superior level of TL proficiency to allow students to become professionals in the use of English in different walks of life. The students all attended an intensive course in English, including separate components for grammar, pronunciation, speaking, reading, writing, and integrated skills as well as in content classes devoted to literature, history, linguistics, and language teaching methodology. The average experience in learning English amounted to around twelve years. TL proficiency was between B2 and C1 according to the Common European Framework of Reference for Languages (Council of Europe, 2001).

\section{Targeted Structure}

The choice of the passive voice as the targeted structure was made because while the participants were familiar with it, its multidimensionality (e.g., requiring a variety of tenses, aspects, and forms to encode meaning) ensured a certain level of variability in its accurate use and mitigated the danger of a ceiling effect. Given the focus of the study, it should be noted that the English passive poses considerable L2 learning difficulty in terms of both explicit and implicit knowledge (Ellis, 2006). Examples of the English passive used in the measures of explicit and implicit knowledge included: is located, must be seen, had been completed, was redecorated, are being planted, or has been bought.

\section{Data Collection and Analysis}

The data collected for the present study were obtained from three sources: (a) two tests of WM (PSTM and WMC), (b) four measures of explicit and implicit knowledge of the 
English passive, and (c) the final grades the participants received in a grammar class. PSTM and WMC were measured with the following two tests:

1) Polish Nonword Span (PNWSPAN; Zychowicz et al., 2018), which included sequences of Polish nonwords (i.e., invented "words" that do not exist in a particular language but that conform to the language's phonological rules). Each nonword was a two-syllable, phonologically likely string of five Polish sounds in a CVCVC order (e.g., nomin, gares, mizek). The nonwords were prerecorded and arranged in sets of two, three, four, five, and six, with three trials per stage. Participants were first presented with two items, and the set sizes were gradually increased to six, with a total of sixty nonwords. Participants were requested to repeat the nonwords in the correct order, with the first sets acting as trial sets. Partial scoring was used, with each item being accorded from zero to three points, depending on the quality of its recall. The Cronbach alpha value was .68;

2) Polish Listening Span (PLSPAN; Zychowicz, et al., 2017), which included nine sets of prerecorded sentences in Polish that increased in size from two to ten sentences each, totaling fifty-four sentences. Some of the sentences were logical while others did not make sense in everyday interaction (e.g., Mark has already taken his exams, so he is going camping versus The goat quickly said that it surely preferred the microphone). Participants had to first decide whether the sentence was logical, then remember its last word (a common noun in the nominative case). Each set was followed by a pause allowing recollection of the final words, with the first two sets serving as trials. Partial scoring was used to reflect the number of remembered words. Internal consistency reliability of the instrument was deemed satisfactory, with the Kuder Richardson Alpha equaling .76.

Four measures were developed to tap into the productive and receptive dimensions of the implicit and explicit knowledge of the English passive voice. In order to ward off a possible transfer effect, tests of implicit knowledge preceded those of explicit knowledge. In addition, those focusing on production came before those requiring reception. The measures are detailed below in Table 1.

The study also attempted to consider a measure of participants' overall mastery of TL grammar, operationalized as the final semester grade received in a grammar class, which constituted an integral component of the intensive English course. Reflecting the grading policies in Polish institutions of higher education, the grades went from 2.0 (lowest or fail), through 3.0, 3.5., 4.0, 4.5, and 5.0 (highest).

Data were analyzed quantitively, which involved computing descriptive statistics for each test and calculating Pearson's correlations between the scores on the tests of WM and the measures of L2 knowledge. This was followed by a series of stepwise regression analyses based on forward selection, with the measures of explicit and implicit knowledge as dependent variables. Since the grades represented an ordinal scale, they were entered into the regression models as dummy variables with the intermediary value of 3.0 being eliminated.

\section{Results}

Table 2 presents the means and standard deviations on the measures of PSTM and WMC, and the tests of L2 knowledge, as well as correlations among these constructs. It immediately becomes clear that the relationships are very weak throughout, even 
Table 1 Implicit and Explicit Knowledge Tests

\begin{tabular}{|c|c|c|c|c|c|c|}
\hline $\begin{array}{l}\text { Knowledge } \\
\text { test }\end{array}$ & Test description & Prompts & Time given & $\begin{array}{l}\text { Response collection } \\
\text { method }\end{array}$ & Scoring & $\begin{array}{l}\text { Cronbach } \\
\text { alpha }\end{array}$ \\
\hline $\begin{array}{l}\text { implicit } \\
\text { productive }\end{array}$ & $\begin{array}{l}\text { focused communication task } \\
\text { (i.e., requires use of the } \\
\text { targeted feature for its } \\
\text { successful completion; } \\
\text { Ellis, 2003) }\end{array}$ & $\begin{array}{l}\text { describe a place } \\
\text { based on } 15 \\
\text { prompts (e.g., } \\
\text { surround by a } \\
\text { garden, can } \\
\text { see from the } \\
\text { highway) }\end{array}$ & $8 \mathrm{~min}$ & $\begin{array}{l}\text { oral performance, } \\
\text { audio-recorded }\end{array}$ & $\begin{array}{l}\text { 1, } 0.5 \text { or } 0 \text { points, } \\
\text { depending on how } \\
\text { serious the error } \\
\text { was (e.g., wrong } \\
\text { tense vs. aspect } \\
\text { vs. entire } \\
\text { construction } \\
\text { incorrect) }\end{array}$ & .84 \\
\hline $\begin{array}{l}\text { implicit } \\
\text { receptive }\end{array}$ & $\begin{array}{l}\text { timed grammaticality } \\
\text { judgment test; } 11 \text { out of } \\
15 \text { sentences were correct } \\
(73 \%)\end{array}$ & $\begin{array}{l}15 \text { sentences in a } \\
\text { PowerPoint } \\
\text { presentation }\end{array}$ & $\begin{array}{l}\text { average of seven } \\
\text { seconds per } \\
\text { sentence } \\
\text { (depending on } \\
\text { sentence } \\
\text { length) }\end{array}$ & $\begin{array}{l}\text { written response } \\
\text { ("correct" vs. } \\
\text { "incorrect") }\end{array}$ & $\begin{array}{l}0 \text { or } 1 \text { point for in/ } \\
\text { correct participant } \\
\text { response }\end{array}$ & .44 \\
\hline $\begin{array}{l}\text { explicit } \\
\text { productive }\end{array}$ & verb form completion task & 15 verbs & untimed & $\begin{array}{l}\text { written performance } \\
\text { ("a traditional } \\
\text { test") }\end{array}$ & $\begin{array}{l}\text { 1, } 0.5 \text { or } 0 \text { points, } \\
\text { depending on how } \\
\text { serious the error } \\
\text { was }\end{array}$ & .95 \\
\hline $\begin{array}{l}\text { explicit } \\
\text { receptive }\end{array}$ & $\begin{array}{l}\text { untimed grammaticality } \\
\text { judgment test with } \\
\text { justifications (i.e., } \\
\text { participants provided a } \\
\text { justification when a } \\
\text { sentence was not } \\
\text { accurate) }\end{array}$ & $\begin{array}{l}15 \text { sentences, } 11 \\
\text { correct and } 4 \\
\text { incorrect }\end{array}$ & untimed & $\begin{array}{l}\text { written response } \\
\text { ("correct" vs. } \\
\text { "incorrect" plus } \\
\text { potential } \\
\text { explanation) }\end{array}$ & $\begin{array}{l}\text { 1, } 0.5 \text { or } 0 \text { points, } \\
\text { depending on } \\
\text { correctness and } \\
\text { plausibility of } \\
\text { explanation }\end{array}$ & .55 \\
\hline
\end{tabular}


Table 2 Correlations ( $r$ ) Among Tests of WM and Measures of L2 Knowledge $(N=171)$

\begin{tabular}{lcccc}
\hline & $\begin{array}{c}\text { Explicit productive } \\
M(S D)\end{array}$ & $\begin{array}{c}\text { Explicit receptive } \\
M(S D)\end{array}$ & $\begin{array}{c}\text { Implicit productive } \\
M(S D)\end{array}$ & $\begin{array}{c}\text { Implicit receptive } \\
M(S D)\end{array}$ \\
& $7.21(2.76)$ & $10.13(1.89)$ & $5.99(2.89)$ & $8.57(1.78)$ \\
\hline $\begin{array}{l}\text { PNWSPAN } \\
M(S D)\end{array}$ & $.15(.0522)$ & $.10(.1802)$ & $.16^{\star}(.0327)$ & $.08(.2733)$ \\
$73.69(16.07)$ & & & & \\
\hline $\begin{array}{c}\text { PLSPAN } \\
M(S D)\end{array}$ & $.24^{*}(.0025)$ & $.14(.0737)$ & $.08(.2737)$ & $.14(.0723)$ \\
$28.84(5.28)$ & & & & \\
\hline
\end{tabular}

Note: An asterisk indicates statistically significant values $(p<.05)$

in cases where they reach significance. Specifically, the PNWSPAN weakly correlated with implicit productive knowledge, but this explained barely $2.6 \%$ of the variance, as is the case with explicit productive knowledge, in which case the result was only marginally significant. The situation looked only a little better for the statistically significant correlation between the PLSPAN and explicit productive knowledge, where about $6 \%$ of the variability was accounted for.

Table 3 presents the optimal models of stepwise regression, with the four types of L2 knowledge representing dependent variables, and the measures of WM and final grades acting as independent ones. When it comes to explicit productive knowledge, the model explains $16 \%$ of the variance, with WMC, measured by the PLSPAN and superior mastery of TL grammar playing a key role. In the case of the receptive dimension of explicit knowledge, the optimal model accounted for $8 \%$ of the variance and it was only the grade, surprisingly 4.0 rather than 5.0 , that proved to be a significant influence. With respect to implicit productive knowledge, the obtained model explained $12 \%$ of the variance, with a high level of mastery of TL grammar and PSTM, operationalized as the PMWSPAN, exerting the greatest impact. Finally, the optimal model for implicit receptive knowledge explained $10 \%$ of the variance, pointing to the sole influence of superior mastery of English grammar.

\section{Discussion}

When it comes to RQ1, PSTM was found to contribute mainly to implicit productive knowledge, accounting for $2.6 \%$ of the variance in scores, and, while this result was marginally significant, it explained a similar amount of variance in the case explicit productive knowledge. WMC only played a part for explicit productive knowledge, accounting for about $6 \%$ of variability in scores. With regards to RQ2, two main observations can be made. First, WM played a significant part only in the model of explicit productive knowledge, where WMC contributed to $16 \%$ of the variance explained. Although WMC also contributed to the model of explicit receptive knowledge and PSTM to that of implicit productive knowledge, its impact was not significant. What is striking is the positive role that higher grades played in all the optimal models, which indicates, perhaps unsurprisingly, that overall mastery of TL grammar is a stronger influence on the knowledge of the passive than WM. All of this indicates that the impact of WM is small, which can perhaps be attributed to the overall high level of proficiency of the participants but also to the fact that many other ID factors (e.g., beliefs, learning styles and strategies, grit) could influence L2 knowledge, which were not 
Table 3 Optimal Models for Types of L2 Knowledge Based on Stepwise Regression Analyses $(N=171)$

\begin{tabular}{|c|c|c|c|c|}
\hline \multicolumn{5}{|c|}{$\begin{array}{l}\text { Explicit productive } \\
R=.42 ; R^{2}=.18 ; \text { adjusted } R^{2}=.16 \\
F(4.166)=8.96 ; p<.00001 ; \text { Standard error of the estimate: } 2.53\end{array}$} \\
\hline & B & Std. error & $t$ & $p$ \\
\hline Grade 5 & 0.36 & 0.09 & 3.87 & $.0002^{\star}$ \\
\hline PLSPAN & 0.17 & 0.08 & 2.31 & $.0220^{\star}$ \\
\hline Grade 4 & 0.12 & 0.07 & 1.57 & .1178 \\
\hline Grade 3.5 & -0.13 & 0.09 & -1.42 & .1584 \\
\hline \multicolumn{5}{|c|}{$\begin{array}{l}\text { Explicit receptive } \\
R=.31 ; R^{2}=.10 ; \text { adjusted } R^{2}=.08 \\
F(3.167)=6.06 ; p<.00061 ; \text { Standard error of the estimate: } 1.81\end{array}$} \\
\hline & B & Std. error & $t$ & $p$ \\
\hline Grade 4 & 0.19 & 0.08 & 2.41 & $.0170^{\star}$ \\
\hline Grade 5 & 0.15 & 0.08 & 1.86 & .0645 \\
\hline PLSPAN & 0.10 & 0.08 & 1.30 & .1965 \\
\hline \multicolumn{5}{|c|}{$\begin{array}{l}\text { Implicit productive } \\
R=.37 ; R^{2}=.14 ; \text { adjusted } R^{2}=.12 \\
F(4.166)=6.79 ; p<.00004 ; \text { Standard error of the estimate: } 2.71\end{array}$} \\
\hline & $B$ & Std. error & $t$ & $p$ \\
\hline Grade 5 & 0.38 & 0.10 & 3.86 & $.0002^{\star}$ \\
\hline Grade 3.5 & -0.25 & 0.10 & -2.53 & $.0123^{\star}$ \\
\hline PNWSPAN & 0.13 & 0.07 & 1.72 & .0869 \\
\hline Grade 4.5 & 0.10 & 0.10 & 1.07 & .2867 \\
\hline \multicolumn{5}{|c|}{$\begin{array}{l}\text { Implicit receptive } \\
R=.33 ; R^{2}=.11 ; \text { adjusted } R^{2}=.10 \\
F(2.168)=10.29 ; p<.000006 ; \text { Standard error of the estimate: } 1.69\end{array}$} \\
\hline & B & Std. error & $t$ & $p$ \\
\hline Grade 5 & 0.40 & 0.09 & 4.36 & $.0000^{\star}$ \\
\hline Grade 3.5 & -0.16 & 0.09 & -1.70 & .0913 \\
\hline
\end{tabular}

Note: An asterisk indicates statistically significant values $(p<.05)$

considered in this study. It would also seem that the impact of WM is more likely for production than comprehension of grammar.

The findings corroborate to some extent the findings of previous research, pointing to the greater role of WMC than PSTM (Linck et al., 2014), as well as showing that the former is a better predictor of explicit, rather than implicit, grammar knowledge (e.g., Li et al. 2019; Martin \& Ellis, 2012; Tagarelli et al., 2015). The fact that the PSTM correlated, however weakly, on the test for implicit productive knowledge could also indicate that, because of the nature of the prompts, participants may have fallen back on well-known chunks to get the message across (Wen \& Li, 2019). This could also explain the fact that, contrary to previous research (e.g., Suzuki \& DeKesyer, 2017), WMC turned out to play no mediating role in tasks that placed the highest demands 
on attentional capacities, that is, measures of productive and receptive implicit knowledge.

\section{Limitations}

The main weakness of this study is related to the design of tasks intended to measure L2 knowledge, particularly those tapping into its receptive dimension, which were clearly lacking in internal consistency $(\alpha=.55$ for explicit knowledge and $\alpha=.44$ for implicit knowledge). One potential reason for this could have been the choice of specific instances of the targeted structure included in the tests, the fact that performance could have been affected by the use of the passive in the preceding productive tasks, or, in the case of the untimed grammaticality judgment test, insufficient optimization of the time accorded to process the sentences containing the targeted feature.

Another vital issue is whether the performance on receptive measures of the knowledge of the passive voice, whether explicit or implicit, could have been impacted to some degree by the productive knowledge of this form, which brings with it a far more important question of how distinct these two dimensions may really be. This issue, though, can only be resolved through further research that would involve other grammatical features in English as well as other languages.

As indicated by the reviewer, perhaps the most important problem in the case of the present study, however, was the way in which the two measures of receptive L2 knowledge were constructed, which could have directly and negatively influenced their internal consistency reliability. First, each of them consisted of just fifteen items, and they may have tapped into two distinct constructs (in this case, the ability to judge correct sentences for grammaticality and the ability to judge incorrect sentences for grammaticality), the scores for which should have been considered separately rather than summed up. This potential lack of unidimensionality could have negatively affected the quality of the measures and might account for the much lower than expected Cronbach alpha values as the coefficient is used to offer insights into the reliability of a single scale (Taber, 2017). In retrospect then, it would have been a better choice to develop measures of the receptive knowledge of the passive that would have included at least thirty items, fifteen representing correct and fifteen incorrect uses of the targeted structure. While the tools employed in the present investigation cannot obviously be changed post hoc, this is an important take-away for future studies striving to tease apart the productive and receptive dimensions of explicit and implicit knowledge. We are fully aware that this explanation does not eliminate the problem in the analyses conducted for the present study.

\section{Conclusion}

Notwithstanding the methodological limitations discussed above, this study aims to contribute to applied linguists' understanding of the role of different facets of WM in explicit and implicit knowledge of TL grammar. Its findings and the issues with methodology underscore the complexity of this relationship, which can be mediated by an array of other ID factors or other variables, like course grades. Further research is clearly necessary to solve this intriguing puzzle, including targeting other structures in different L2s, involving learners at different levels, accounting for other potential mediating variables that may impact WM and, of course, advancing in methodology and test construction based on the lessons learned here. 
Acknowledgments. The study reported in this paper represents a contribution to the research project no. 2015/17/B/HS2/01704 (2016-2019) funded by the National Science Centre, Poland.

\section{References}

Baddeley, A. D. (2015). Working memory in second language learning. In Z. Wen, M. B. Mota, \& A. McNeill (Eds.), Working memory in second language acquisition and processing (pp. 17-28). Multilingual Matters.

Council of Europe. (2001). Common European Framework of Reference for Languages: Learning, Teaching, Assessment. Cambridge University Press.

DeKeyser, R. (2017). Knowledge and skill in SLA. In S. Loewen \& M. Sato (Eds.), The Routledge handbook of instructed second language acquisition (pp. 15-32). Routledge.

Ellis, R. (2003). Task-based language learning and teaching. Oxford University Press.

Ellis, R. (2005). Measuring implicit and explicit knowledge of a second language: A psychometric study. Studies in Second Language Acquisition, 27(2), 141-72.

Ellis, R. (2006). Modeling learning difficulty and second language proficiency: The differential contributions of implicit and explicit knowledge. Applied Linguistics, 27, 431-63.

Ellis, R. (2008). The study of second language acquisition (2nd ed.). Oxford University Press.

Li, S., Ellis, R., \& Zhu, Y. (2019). The associations between cognitive ability and L2 development under five different instructional conditions. Applied Psycholinguistics, 40(3), 693-722.

Linck, J. A., Osthus, P., Koeth, J. T., \& Bunting, M. F. (2014). Working memory and second language comprehension and production: A meta-analysis. Psychonomic Bulletin \& Review, 21(4), 861-83.

Martin, K. I., \& Ellis, N. C. (2012). The roles of phonological STM and working memory in L2 grammar and vocabulary learning. Studies in Second Language Acquisition, 34(3), 379-413.

Pawlak, M. (2020). Individual differences and good language teachers. In C. Griffiths \& Z. Tajeddin (Eds.), Lessons from good language teachers (pp. 121-132). Cambridge University Press.

Pawlak, M., \& Biedroń, A. (2019). Verbal working memory as a predictor of explicit and implicit knowledge of English passive voice. Journal of Second Language Studies, 2, 258-280.

Suzuki, Y., \& DeKeyser, R. (2017). Exploratory research on second language practice distribution: An Aptitude $\times$ Treatment Interaction. Applied Psycholinguistics, 38(1), 27-56.

Taber, K. S. (2017). The use of Cronbach's Alpha when developing and reporting research instruments in science education. Research in Science Education, 48, 1273-1296.

Tagarelli, K. M., Borges Mota, M., \& Rebuschat, P. (2015). Working memory, learning conditions, and the acquisition of L2 syntax. In Z. Wen, M. Borges Mota, \& A. McNeill (Eds.), Working memory in second language acquisition and processing: theory, research and commentary (pp. 224-247). Multilingual Matters.

Wen, E. Z., Biedroń, A, \& Skehan, P. (2017). Foreign language aptitude theory: Yesterday, today and tomorrow. Language Teaching, 50, 1-31.

Wen, Z., \& Li, S. (2019). Working Memory in L2 Learning and Processing. In J. Schwieter \& A. Benati (Eds.), The Cambridge Handbook of Language (pp. 365-389). Cambridge University Press.

Zychowicz, K., Biedroń, A, \& Pawłak, M. (2017). Polish Listening SPAN: A new tool for measuring verbal working memory. Studies in Second Language Learning and Teaching, 7, 601-618.

Zychowicz, K., Biedroń, A, \& Pawłak, M. (2018). Polish Nonword Span (PNWSPAN): A new tool for measuring phonological loop capacity. Glottodidactica, XLV/2, 309-327.

Cite this article: Pawlak, M., \& Biedroń, A. (2021). Working memory as a factor mediating explicit and implicit knowledge of English grammar. Annual Review of Applied Linguistics, 41, 118-125. https:// doi.org/10.1017/S0267190521000052 